${ }^{1}$ Faculty of Health and

Medicine, Lancaster

University, Lancaster,

Lancashire, UK

${ }^{2}$ School of Nursing, Sue

Ryder Care, University of

Nottingham, Nottingham, UK

${ }^{3}$ School of Nursing, Midwifery and Social Work, University of

Manchester, Manchester, UK

${ }^{4}$ Division of Primary Care,

University of Liverpool,

Liverpool, Merseyside, UK

${ }^{5}$ Faculty of Health Sciences,

University of Southampton,

Southampton, UK

${ }^{6}$ School of Nursing and

Midwifery, University

of Southampton,

Southampton, UK

\section{Correspondence to}

Sheila Payne, Faculty of Health and Medicine,

Lancaster University,

Lancaster, Lancashire, UK;

s.a.payne@lancaster.ac.uk

Accepted 10 June 2012

\title{
An evaluation of research capacity building from the Cancer Experiences Collaborative
}

\author{
Sheila Payne, ${ }_{1}^{1}$ Jane Seymour, ${ }^{2}$ Gunn Grande, ${ }^{3}$ Katherine Froggatt, ${ }_{1}^{1}$ Alex Molassiotis, ${ }^{3}$ \\ Mari Lloyd-Williams, ${ }^{4}$ Claire Foster, ${ }^{5}$ Julia Addington-Hall, ${ }^{6}$ Elizabeth Rolls, ${ }^{1}$ Chris Todd ${ }^{3}$
}

\section{INTRODUCTION}

The National Cancer Research Institute's (NCRI) strategic review identified the need to build research capacity in UK supportive and palliative care research. ${ }^{1}$ Only $4.3 \%$ of direct spending on cancer research by NCRI partners (about $£ 11$ million per year) was being directed at supportive and palliative care, and weaknesses in the field included:

- The predominance of small-scale and often poor quality studies with less attention to research into meeting patient's needs

- Lack of a critical mass of experienced research groups and researchers, with internationallevel performance and little integration with the wider research community and other disciplines

- Lack of user involvement

- Lack of strong leadership, and

- Competition for limited resources. ${ }^{1}$

To redress these, NCRI recommended the establishment of interdisciplinary, supportive and palliative care, research collaboratives which were to include academic organisations, researchers and individuals, and groups from different research disciplines and clinical professions, whose purpose would be to enhance the value, quality and productivity of UK cancer-related supportive and palliative care research. ${ }^{2}$

We have described the financial and personal challenges of building collaborative research more fully elsewhere. ${ }^{3}$ This paper uses an evaluative framework ${ }^{4}$ to describe Cancer Experiences Collaborative's (CECo) activities, and assess the extent to which CECo has built research capacity in supportive and palliative care. It considers the legacy of CECo in the context of the wider discussions about value of collaborative research, and offers a critical appraisal of this type of funding model.

\section{THE CANCER EXPERIENCES COLLABORATIVE}

CECo was one of two UK interdisciplinary research groups that was awarded NCRI collaborative funding (2006-2011) of $£ 1.9$ million. It comprised a partnership between researchers at five UK universities (Lancaster, Liverpool, Manchester, Nottingham and Southampton), clinical organisations (including the four largest hospices in England, and cancer centres); Help the Hospices (a leading charity supporting UK hospice care), and user representatives, with a total of 26 organisations represented among grant-holders and named collaborators.

While funding is normally provided for scientific research programmes, the aim of NCRI's investment in CECo was to develop a collaborative infrastructure that supported research capacity building through which individuals and teams could gain additional project-specific funding to take forward supportive and palliative care research. CECo identified four areas for development:

- Increase research grant income

- Increase the quality and quantity of publications

- Build research skills and grantsmanship in individuals and teams, and

- Improve user involvement.

Three research themes were identified through which to focus activity: 'Innovative approaches to complex symptoms'; 'Older People towards the end of life: priorities, processes and places' and 'Innovations in Methodology'. Details of these can be found on the CECo website (http://www. ceco.org.uk). Between May 2006 and September 2011, CECo members generated $£ 18762705$ in new research income. Of this total, £4 378951 arose directly from CECo activities and involved cross-institutional work, and was related to one of CECo's priority areas, while a further $£ 14383754$ benefitted indirectly from links to CECo, by being outwith CECo's main areas of work or involved only one organisation. The latter category 'benefitting from CECo activities' accounted for the majority of research income generated and demonstrates the added value of the intrastructure support, networking, methodological expertise and senior research mentorship that accrued from this collaborative. The distribution of this additional external income over 5 years is shown in figure 1.

\section{THE EVALUATIVE FRAMIEWORK}

The definition of research capacity building (RCB), adopted by the UK Department of Health is 'a process of individual and institutional development which leads to higher levels of skills and greater ability to perform useful research' (p. 1321). ${ }^{5}$ In attempting to describe the outcomes and benefits of RCB, Cooke argues that it is both a means to an end (useful research that informs practice and informs health gain), and an end in itself (by developing structures and skills enabling research to take place). ${ }^{4}$ As a result, any framework for measuring RCB should be inclusive of process (the steps and mechanisms) and outcome measures (the goals). To meet the challenges of measuring progress and identifying appropriate outcomes, Cooke has provided a framework that identifies four structural levels at which RCB initiatives provide support and can therefore be assessed: individual, team, organisation and supra- 


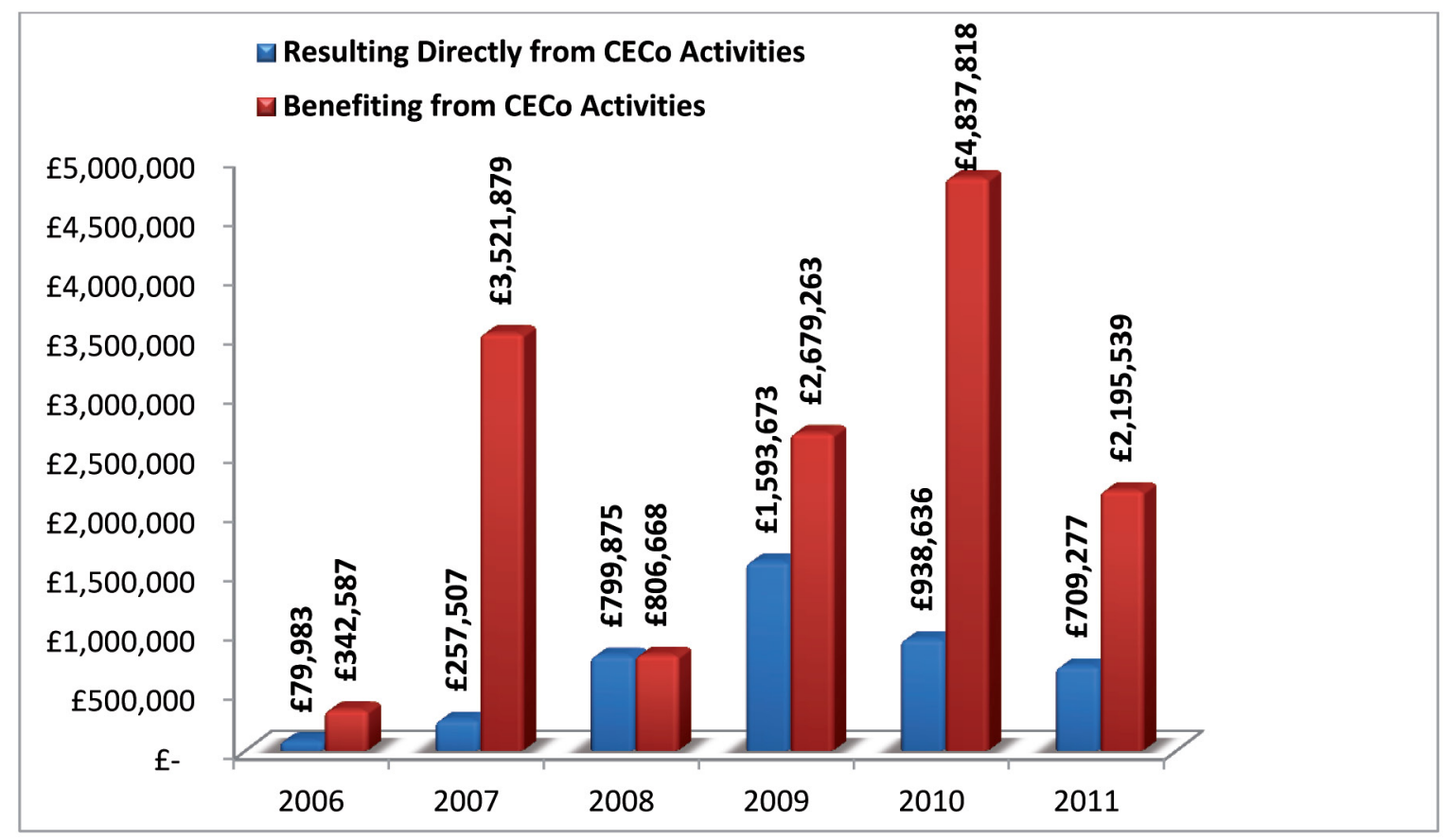

Figure 1 CECo's additional external income by year (May 2006-September 2011).

organisational/network. ${ }^{4}$ Across these, there are six principles of $\mathrm{RCB}$, and we will draw on these to consider the efforts of the CECo Collaborative. These principles are:

- Building skills and confidence through training, and creating opportunities to apply skills

- Supporting research 'close to practice' in order for it to be useful

- Establishing linkages, partnerships and collaborations to enhance RCB

- Ensuring appropriate dissemination to maximise impact

- Building elements of sustainability and continuity, and

- Investing in appropriate infrastructure to enhance RCB. ${ }^{4}$

Within each principle, Cooke's framework provides examples of activities and suggestions for measurement criteria that could be included. ${ }^{4}$ These principles and examples of measurement criteria are outlined in table 1.

CECo's activities, outlined in the Annual and Final Reports and other CECo records, will be assessed using these suggested criteria.

\section{CECO'S BUILDING RESEARCH CAPACITY ACTIVITIES}

Developing appropriate skills and confidence through training, and creating opportunities to apply skills

One of the central aims of Cancer Experiences Collaborative (CECo) was to build research capacity in supportive and palliative care research in a new generation of researchers, by providing opportunities for them to develop their expertise and skills and deeper understanding of applied research under the leadership of experienced researchers. CECo made a decision to focus on developing clinicians and researchers at the early stages of their career, and within each of CECo's Research Themes, researchers and partners, drawn from more than 20 different academic and clinical backgrounds as well as service users, have been actively engaged in research.

CECo activities also involved specific research training at introductory, doctoral and postdoctoral levels, through master classes, Economic and Social Research Council (ESRC) seminar series, $\mathrm{PhD}$ and postdoctoral methodology workshops, the mentorship of novice researchers (particularly in hospices) through doctoral studies, postdoctoral fellowships, and the identification of 'rising stars' among senior lecturers and readers. The suitability of research methods used in supportive and palliative care research, and evidence that contributed to improving the research process and outcome were also explored, including issues relating to quantitative or qualitative research methodologies, ${ }^{67}$ participant understanding of research design or terminology; the involvement of service users in research; and the use of innovative research methods or approaches.

Fifteen clinicians were awarded time-limited scholarships; this bought out their time from clinical work to enable them to undertake a small project under the mentorship of CECo senior researchers. An investment of $£ 150000$ has resulted, to date, in 16 peer-reviewed publications and five further grants awarded to the scholars to the value of $£ 50000$. These scholars have also made presentations at major conferences, including those organised by National Cancer Research Institute, European Association of Palliative Care, Multinational Association of Supportive Care in Cancer, European Cancer Organisation, Palliative Care Research Society, British Psychosocial Oncology Society, Help the Hospices and the International Advance Care Planning Association.

I was lucky to have been awarded the CECo scholarship, which enabled me to work on a research project that I initially developed during my academic foundation doctor training. The CECo scholarship has also helped me to gain generic skills in undertaking research work, and I hope that I can continue to build on them through submitting a $\mathrm{PhD}$ proposal in the near future. I believe scholarships, such as CECo's are invaluable in developing research capacity and encouraging junior researchers to progress in academia. CECo Scholar. 
Table 1 Principles of research capacity building and examples of measurement criteria

Principle
opportunities to apply skills

2. Supporting research 'close to practice' in order for it to be useful

3. Establishing linkages, partnerships and collaborations to enhance RCB

4. Ensuring appropriate dissemination to maximise impact

5. Building elements of sustainability and continuity

6 . Investing in appropriate infrastructure to enhance RCB (Cooke, 2005)

\section{Examples of measurement criteria}

Evidence of progressive skill development

Research undertaken

Skill mix of team

Availability and use of training funds

Evidence of outreach work undertaken in organisations

Evidence of secondment opportunities offered and taken up

Evidence of patient-centred outcome measures in projects, and impact of project on patients' quality of life, including social capital and health gain

Evidence on level, and nature, of service user involvement

Evidence of supporting service user links in research

Evidence of research questions being developed with practice, needs and priorities

Development and use of cost-effective methodologies

Evidence of increased number of research partnerships

Evidence of inter-professional working

Links with universities/ Research Design Support Units (RDSUs)

Work with funding bodies

Evidence of research collaboration with practitioners, teams, networks and organisations in healthcare practice

International links

Papers in research and practice journals

Conference presentations

Applied dissemination of findings

Seminar programmes relating to research undertaken

Papers focusing on health services research, written with practitioners

Conference presentations at practice-focused conferences

Successful access to funding for continued application of skills (grants and fellowships)

Examples of continued support and supervision arrangements

Examples of continued collaboration

Linked support within career pathways

Fellowships supported

Evidence of project management (objective setting with timescales)

A description of mentorship and supervision structures

Evidence of R\&D information dissemination strategies

The nature of collaborations (coauthorship, order of authorship)

Organise information exchange events

RCB, research capacity building.

The development of expertise and confidence has had a major impact on the research careers of CECo's scientific staff, with at least five new Chairs, and career progression to lecturer and senior lecturer roles for more than 10 people. In addition, it has influenced practice by engaging clinicians in research and, conversely, embedding researchers more within clinical practice.

\section{Supporting research 'close to practice' in order for it to be useful}

CECo was concerned to generate research that moved beyond describing patient need towards developing and testing effective solutions using appropriate study designs. The Innovative Approaches to Complex Symptoms Research Theme secured funds to undertake research with a strong policy and theoretical emphasis in the areas of: non-pharmacological interventions; assessment methods for complex symptoms; self-management of cancer-related problems; and research into non-cancer symptom management. ${ }^{8-10}$ The Older People towards the end of life: priorities, processes and places research theme developed a programme of work relating to the improved care and support, towards the end of life, of older people and their informal family carers, taking into account socio-demographic and ethnic diversity, and introducing methodological innovation, especially in user involvement. It sought to provide new evidence to address issues and, working with policy makers and practitioners, to disseminate findings and their implications for best practice and policy. ${ }^{11-13}$ The Methodology Research Theme investigated methodological and practical challenges in conducting research in supportive and palliative care, including recruitment, outcome assessment and study adherence. It initially focused on improving understandings about narrative methodology, and investigating the application of narrative methods in supportive and palliative care. ${ }^{14-16}$ More recently, the focus expanded to study the suitability of a variety of methods used in supportive, palliative and end-of-life care research, and to provide evidence that contributes to improving the research process and outcome.

CECo has also had an impact on the wider scientific community through its development of end-of-life care research methodologies, links to wider methodological debates and innovations and facilitation of a considerable volume of research of international significance. At present, however, it is too early to assess the extent to which CECo has contributed to improving the illness experience for patients and their families. This is partly because there is a time lag between research and its integration into practice, but also because it is more difficult to demonstrate changes to clinical practice as a result of research. Nevertheless, some influences are being detected, for example, on policy ${ }^{17}$ and in clinical guidelines for supportive care in multiple myeloma, ${ }^{18}$ and National Cancer Survivorship Initiative participating in the 


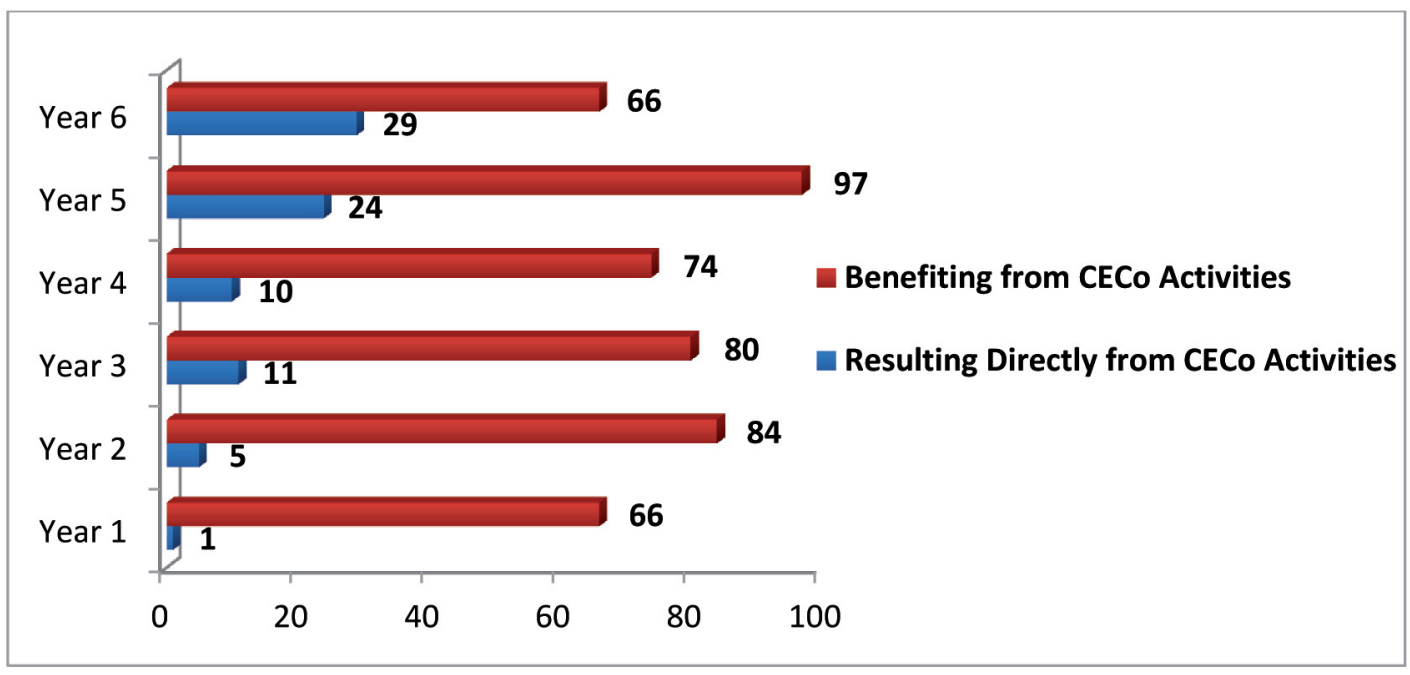

Figure 2 CECo academic publications by year (May 2006-September 2011).

NCRI rapid review to determine research priorities for cancer survivorship. ${ }^{19} 20$

Despite the challenges it entailed, ${ }^{3}$ service users-including patients, carers, health and social care professionals, support workers, voluntary organisations and advocacy groups-were integral to the research process through their involvement in all stages. This included participating in CECo management, advising on CECo scholarship awards, and reviewing and advising on all aspects of CECo research by: ensuring that research proposals addressed questions of importance to those most affected by cancer; helping to refine research questions; developing new measures grounded in firsthand experience; and improving the quality of information for research participants. Their contribution was enhanced through a series of supportive activities that enabled them to learn about research, committee and academic procedures. Training to support user contributions included preparing user-led research proposals, and a number of users have had abstracts accepted at NCRI and other conferences, and submitted research proposals in their own right.

\section{Developing linkages, partnerships and collaborations to enhance RCB}

Collaboration in research is not a new phenomenon, and there are many national and international examples of large programme grants and international studies, including those funded by the European Commission. ${ }^{21}$ However, the distinctive feature of CECo-placing RCB not only as a means to an end, but as an end in itself ${ }^{4}$-has meant that developing linkages, partnerships and collaborations, within and outwith the CECo collaborative had a developmental as well as a functional status. With the focus upon building internal linkages, there was the real danger that exclusion of individual researchers outwith CECo could happen, and this may have been an unfortunate and unintended consequence of such collaboration.

Within CECo, the development of the research community was facilitated through the provision of a website that provided increasingly sophisticated facilities for joint working. An on-line forum enabled researchers, service users and clinicians to contribute to collaborative projects, engage in discussion and facilitated information transfer. As a direct result of CECo, extensive collaborative links have been developed and maintained across the UK. International-level research experience has also been gained through increasing links with international scholars and the development of collaborative initiatives. Examples of these include: a joint workshop with researchers from The Netherlands/Belgium which led to the development of a number of grant proposals, and strengthened epidemiological/public health expertise leading to an international study on the perspectives of older people on end-of-life care, ${ }^{22}$ and an ongoing international study which examines the contentious issue of palliative sedation in end-of-life decision making. ${ }^{23}$

\section{Ensuring appropriate dissemination to maximise impact}

A key stage in research is its dissemination through strategies that are "fit for purpose' 4 and, to date, 547 papers have been published in academic and professional journals, of which 80 $(15 \%)$ are a direct result of CECo activity and 467 (85\%) have benefitted from CECo activities. Furthermore, as figure 2 identifies, the number of papers resulting directly from the work of CECo has risen steadily during this period. Similar growth in conference presentations and membership of prestigious committees was evident but not illustrated here.

\section{Building elements of sustainability and continuity}

While the impact of research on policy and practice is difficult to assess, particularly in the early stages, CECo has made a significant contribution to policy, guidelines, practice development and educational and information materials for professionals, patients and the general public. ${ }^{24} 25$ This has been achieved through the promotion of evidence-based practice to benefit patient care that has also been relevant to the decision making of practitioners and policy makers. For example, research on Cancer Survivorship has informed the emerging strategic direction taken by Macmillan Cancer Support and the National Cancer Survivorship Initiative. ${ }^{19} 26$ Research and scholarship on decision making for frail older people who lack capacity has informed a Council of Europe Symposium on medical decision making at the end of life, ${ }^{27}$ and the development of guidance for health and social care staff about decision making and advance care planning in life-limiting illness. ${ }^{28}$ This links to an extensive consultation process and wide involvement in national and international research and education activities to promote and 
develop advance care planning. ${ }^{29}$ Related public information has also been developed and distributed nationally, ${ }^{30}$ and this has been subject to an independent evaluation. ${ }^{31}$

\section{Investing in appropriate infrastructures to enhance RCB}

Each of the CECo Research Themes was led by senior people with designated responsibility for providing academic leadership, together with a small team of researchers who were responsible for taking forward the programme of collaborative research development, research capacity building activities, and other events consistent with each group's special remit. ${ }^{32}$ Alongside research and collaborative skills, CECo has built leadership capacity in many ways, including through investment in leadership training with expert facilitators, and devolving budgets to theme leaders who have learnt to inspire and motivate their teams, manage people from different backgrounds, motivations and skills, and resolve conflicts as they arise.

\section{DISCUSSION}

Within our original aim of making significant and substantial progress in the quality of research in supportive and palliative care, ${ }^{3}$ a central focus has been on RCB. CECo has been an unprecedented model for collaborative research engagement between universities and local research users in different supportive and palliative care settings for which, it could be argued, the extensive research activity has been a means to an end-the development, not only of a critical mass of research, but of a critical mass of researchers who have developed their skills, understanding and confidence in research. As a direct result of CECo, research capacity has been increased, and the quality and volume of UK collaborative supportive and palliative care research has been enhanced.

Within programmes of research, there are many reasons for collaboration, including: enabling large-scale, multicentre studies to bring together a team of experts and access large samples; attracting funding; ${ }^{33} 34$ and enabling the development of cyberinfrastructure in order to adopt standard measures, vocabularies and systems. ${ }^{35}$ Despite a general reduction in the availability of research money and more intense competition for limited resources, working collaboratively has enabled CECo researchers to secure more substantial grants to undertake research that is having an impact on policies and practice. Arguably, these successes might have occurred anyway for senior investigators, but it is unlikely that research capacity will have been promoted in such an equitable way.

Cooke's framework ${ }^{4}$ has been useful in assessing the process as well as the outcomes of CECo's RCB activities. Although it has been patchy, with some principles being less well developed, and with less engagement from medical professionals than anticipated, but where they have engaged, CECo can demonstrate the consistent development of the span and skills of individual (academic, clinician and user) researcher expertise in supportive and palliative care, increased leadership capacity in senior researchers, and stronger links with international scholars and research initiatives. However, it takes longer to demonstrate the impact of the investment in young researchers and, perhaps most disappointingly, there has been an uncertain 'translation' of effort with non-active researchers into active researchers. More targeted support is needed to encourage practitioners to engage with research, while maintaining clinical roles. While a CECo-funded comparison of publicly available data on palliative care publications submitted by universities for the 2001 and 2008 Research Assessment
Exercises showed little growth in research capacity, ${ }^{36}$ analysis of Research Excellence Framework (REF) 2014 data will be informative as a concrete measure of the outcome of CECo on the vibrancy of UK research and UK researchers. It is acknowledged that different organisations will judge the success of CECo outputs by different criteria dependent upon the 'unit of assessment' (the comparator group) to which individuals and research groups will be returned in the forthcoming REF.

Discussions about collaborative research usually begin at the point of how, with whom and on what to collaborate, and rarely, if ever, do they consider equally important questions of where the impetus and emphasis for collaboration is coming from, and how it is connected to the political research context. ${ }^{37}$ Recently, questions have begun to be asked about the value of collaboration in research. On the one hand, there is a view that concentration of research funding in a few elite universities fuels an obsession with institutional competition, rather than with the real world of partnerships, ${ }^{38}$ while on the other hand, there is a need to reform the 'exhausted' top-down funding mechanisms that force researchers into collaborations. ${ }^{39}$ Building a collaborative for RCB is time consuming, and presents many challenges ${ }^{3}$ through the outworking of the politics of collaboration. ${ }^{40}$ During CECo's first and second years, there were few research outputs-the focus of effort was on organising and hosting meetings, building trust, negotiating tensions and identifying common interests. Many lessons were learnt, including how to focus effort most fruitfully. One of the tensions in RCB is whether to concentrate effort on the 'brightest and best', or to enable people at all stages of their careers to broaden their research knowledge. CECo chose to focus on the development of research knowledge at all levels, including within hospice settings-an area underserviced by NHS support. RCB also entails certain costs: it takes people out of their comfort zone; distracts them from their own interests; and, for senior researchers, 'valuable' time is taken up with developing governance arrangements, managing people and projects effectively across institutions in the absence of line-management responsibility, and mentoring and helping to improve the grants of others, often at the expense of their own research and grant applications.

There are different models for collaborative research, for example, the three-dimensional framework of O'Sullivan et $a l^{41}$ which is based on: the number of different administrative units represented in the research team (institutional context); the number of academic fields present on the research team (homogeneous or heterogeneous), and the manner in which the work is performed and knowledge is created (disciplinarity). However, the question of appropriate models of collaboration for research capacity building remains unanswered and needs to be addressed. The CECo model, which privileges the processes of research collaboration as central to RCB, has attracted increasing international interest, and the models of governance, leadership and user involvement developed within CECo is beginning to be applied beyond the UK, including the newly formed All-Ireland Institute of Hospice and Palliative Care (see http://www.aiihpc.org) and in Australia.

\section{CONCLUSION}

As a direct result of CECo, the capacity of UK researchers has been increased, and the quality and volume of collaborative supportive and palliative care research has been enhanced. CECo has also had wider influence on research, policy and practice within and beyond the UK. Time will tell what the extent of the impact of CECo has been, but it is unlikely that 
the benefits that are already evident would have occurred without the NCRI investment in the infrastructures of CECo. As we enter a period of increasing austerity, the challenge is to retain collaboration to support RCB rather than revert to smallscale single-researcher studies with potentially less impact.

Acknowledgements The authors thank all members of the Cancer Experiences Collaborative. Special thanks go to Anthony Greenwood, Anne-Marie McDonnell and Jan Lyons for their help in the preparation of this paper.

Funding National Cancer Research Institute.

Competing interests The author has served on the NCRI Palliative Care Clinical Studies Group from 2008 to 2012 and the Association for Palliative Medicine Science Committee from 2005 to 2012. He is a grant holder from the following awarding bodies: Cancer Research UK, Marie Curie Cancer Care and HTA.

Provenance and peer review Not commissioned; externally peer reviewed.

\section{REFERENCES}

1. National Cancer Research Institute. Supportive and palliative care research in the UK: Report of the NCRI strategic planning group on supportive and palliative care. London: NCRI 2004.

2. National Cancer Research Institute. 3 year progress report 2001-2004. London: NCRI 2004.

3. Payne S, Seymour J, Molassiotis A, et al. Benefits and challenges of collaborative research: lessons from supportive and palliative care. BMJ Support Palliat Care 2011;1:5-11.

4. Cooke J. A framework to evaluate research capacity building in health care. BMC Fam Pract 2005;6:44.

5. Trostle J. Research capacity building in international health: definitions, evaluations and strategies for success. Soc Sci Med 1992;35:1321-1324.

6. Grande G, Preston N. The need for new perspectives on evaluation of palliative care. Palliat Med 2011;25:737-738.

7. Payne S. The Cancer Experiences Collaborative: better research, by better researchers. Palliat Med 2011;25:739-740.

8. Irving G, Lloyd-Williams M. Depression in advanced cancer. Eur J Oncol Nurs 2010;14:395-399

9. Foster C, Fenlon D. Recovery and self-management support following primary cancer treatment. Br J Cancer 2011;105(Suppl 1):S21-S28.

10. Lloyd-Williams M, Shiels C, O'Conor C, et al. A pilot RCT to explore impact of an intervention for suffering in advanced cancer. J Pain Symptom Manage (In Press).

11. Kennedy S, Bird L, Cox K, et al. Improving support for older people looking after someone with advanced cancer. 2011. University of Nottingham http://www. endoflifecareforadults.nhs.uk/assets/downloads/older carers support needs.pdf (accessed 8 November 2011).

12. Rolls $\mathbf{L}$, Seymour JE, Froggatt $K A$, et al. Older people living alone at the end of life in the U.K.: research and policy challenges. Palliat Med 2011;25:650-657.

13. Seymour J, Almack K, Kennedy S. Implementing advance care planning: a qualitative study of community nurses' views and experiences. BMC Palliat Care 2010;9:4.

14. Bingley AF, Thomas C, Brown J, et al. Developing narrative research in supportive and palliative care: the focus on illness narratives. Palliat Med 2008;22:653-658

15 Rolls L, Payne S, Brown J. Narrative Methods in Supportive and Palliative Care: an Annotated Bibliography. Observatory Publications: Lancaster University 2009.

16. Thomas C, Reeve J, Bingley A, et al. Narrative research methods in palliative care contexts: two case studies. J Pain Symptom Manage 2009;37:788-796.

17 NHS End of Life Care Strategy - promoting high quality care for all adults at the end of life. 2008. http://www.dh.gov.uk/prod_consum_dh/groups/dh_digitalassets/@ dh/@en/documents/digitalasset/dh 086̄345.pdf (accessed 12 December 2011).

18. Snowden JA, Ahmedzai SH, Ashcroft J, et al. Guidelines for supportive care in multiple myeloma 2011. Br J Haematol 2011;154:76-103.
19 Richardson A, Addington-Hall J, Stark D, et al. Determining research priorities for cancer survivorship: consultation and evidence review. National Cancer Survivorship Initiative 2010

20. Richardson A, Addington-Hall J, Amir Z, et al. Knowledge, ignorance and priorities for research in key areas of cancer survivorship: findings from a scoping review. Br J Cancer 2011;105 Suppl 1:S82-S94.

21 Lynch T, Payne S, Scholte W, et al. ATOME training of lawyers and national counterparts workshop: a report. Eur J Pall Care 2011;18:31-35.

22. Pleschberger S, Seymour JE, Payne S, et al. Interviews on end-of-life care with older people: reflections on six european studies. Qual Health Res 2011;21:1588-1600.

23. Seymour J, Rietjens J, Brown J, et al. The perspectives of clinical staff and bereaved informal care-givers on the use of continuous sedation until death for cancer patients: The study protocol of the UNBIASED study. BMC Palliat Care 2011;10:5

24. Payne S. EAPC Task Force on Family Carers White Paper on improving support for family carers in palliative care: part 1. Eur J Pall Care 2010;17:238-245.

25. Payne S. EAPC Task Force on Family Carers White Paper on improving support for family carers in palliative care: part 2. Eur J Pall Care 2010;17:286-290.

26. Foster C, Sayers M, Robinson J, et al. Supporting relatives: An investigation into obstacles and aids to information exchange within families affected by cancer. Report for Macmillan Cancer Support 2010.

27. Council of Europe. Symposium on the decision-making process regarding medical treatment in end of life situations, Strasbourg (France), 30 November-1 December 2010. http://www.coe.int/t/dg3/healthbioethic/Activities/09 Euthanasia/default en.asp (accessed 14 November 11).

28. NHS. Capacity, care planning and advance care planning in life limiting illness: A Guide for Health and Social Care Staff. 2011. http://www.endoflifecareforadults. nhs.uk/publications/pubacpguide (accessed 14 November 2011).

29. International Society of Advance Care Planning and End of Life Care. Inaugural International Conference on Advance Care Planning 2010. http://www. acpelsociety.com/ (accessed 14 November 2011).

30. NHS. Planning For Your Future Care: A Guide. 2009. http://www. endoflifecareforadults.nhs.uk/publications/planningforyourfuturecare laccessed 14 November 2011).

31. NHS. An evaluation of 'Planning for your Future Care: A Guide'. Final report. 2010 http://www.endoflifecareforadults.nhs.uk/publications/planning-for-your-futurecare-evaluation (accessed 14 November 2011).

32. Bailey C, Wilson R, Addington-Hall J, et al. The Cancer Experiences Research Collaborative (CECo): Building research capacity in supportive and palliative care. Prog Pall Care 2007: 14(6) 265-270.

33. Smith $\mathbf{D}$. Collaborative research: Policy and the management of knowledge creation in UK universities. Higher Ed Quart 2001;55:131-157.

34. Morse JM. Styles of collaboration in qualitative inquiry. Qual Health Res 2008:18:3-4.

35. Schad PA, Mobley LR, Hamilton CM. Building a biomedical cyberinfrastructure for collaborative research. Am J Prev Med 2011;40:S144-S150.

36. Clark D, Clark J, Greenwood A. The place of supportive, palliative and end-of-life care research in the United Kingdom Research Assessment Exercise, 2001 and 2008. Palliat Med 2010;24:533-543.

37. Cheek J. Researching collaboratively: implications for qualitative research and researchers. Qual Health Res 2008:18:1599-1603.

38. Baker S. Policymakers urged to embrace collaboration. 2011. http://www. timeshighereducation.co.uk/story.asp?sectioncode $=26 \&$ storycode $=418370 \& \mathrm{c}=$ 1 (accessed 12 December 2011).

39. Jump P. Research suffers if scientists are forced to marry for money. 2011. http:// www.timeshighereducation.co.uk/story.asp?sectioncode $=26$ \&storycode $=41829$ $8 \& \mathrm{C}=1$ (accessed 12 December 2011).

40. Beattie J, Cheek J, Gibson T. The politics of collaboration as viewed through the lens of a collaborative nursing research project. J Adv Nurs 1996;24:682-687.

41. O'Sullivan PS, Stoddard HA, Kalishman S. Collaborative research in medical education: a discussion of theory and practice. Med Educ 2010;44:1175-1184. 
BMJ Supportive \& Palliative Care

\section{An evaluation of research capacity building from the Cancer Experiences Collaborative}

Sheila Payne, Jane Seymour, Gunn Grande, et al.

BMJ Support Palliat Care published online July 16, 2012

doi: 10.1136/bmjspcare-2012-000236

Updated information and services can be found at:

http://spcare.bmj.com/content/early/2012/07/16/bmjspcare-2012-000236.full.html

\section{These include:}

References This article cites 26 articles, 9 of which can be accessed free at: http://spcare.bmj.com/content/early/2012/07/16/bmjspcare-2012-000236.full.html\#ref-list-1

$\mathbf{P}<\mathbf{P} \quad$ Published online July 16, 2012 in advance of the print journal.

Email alerting
service

Receive free email alerts when new articles cite this article. Sign up in the box at the top right corner of the online article.

Notes

Advance online articles have been peer reviewed, accepted for publication, edited and typeset, but have not not yet appeared in the paper journal. Advance online articles are citable and establish publication priority; they are indexed by PubMed from initial publication. Citations to Advance online articles must include the digital object identifier (DOIs) and date of initial publication.

To request permissions go to:

http://group.bmj.com/group/rights-licensing/permissions

To order reprints go to:

http://journals.bmj.com/cgi/reprintform

To subscribe to BMJ go to:

http://group.bmj.com/subscribe/ 